\title{
Clinical and Etiological Characteristics of Hemiplegia at the University Regional Hospital Center Ouahigouya
}

\author{
Alassane Dravée ${ }^{*}$, Christian Napon², Anselme A. Dabilgou'², Salam Ouedraogo1, Jean B. Kaboré2 \\ ${ }^{1}$ Department of General Medicine of the Ouahigouya Regional University Hospital Center, Ouahigouya, Burkina Faso \\ ${ }^{2}$ Neurology Department of Yalgado OUEDRAOGO Ouagadougou University Hospital Center, Ouagadougou, Burkina Faso \\ Email: *aladraves@yahoo.fr
}

How to cite this paper: Dravé, A., Napon, C., Dabilgou, A.A., Ouedraogo, S. and Kaboré, J.B. (2020) Clinical and Etiological Characteristics of Hemiplegia at the University Regional Hospital Center Ouahigouya. World Journal of Neuroscience, 10 , 22-28.

https://doi.org/10.4236/wjns.2020.101004

Received: November 22, 2019

Accepted: January 5, 2020

Published: January 8, 2020

Copyright $\odot 2020$ by author(s) and Scientific Research Publishing Inc. This work is licensed under the Creative Commons Attribution International License (CC BY 4.0).

http://creativecommons.org/licenses/by/4.0/ (C) (i) Open Access

\begin{abstract}
Objective: To describe the clinical and etiological characteristics of hemiplegia in the northern region of Burkina Faso. Methodology: This was transversal with a descriptive and analytical study of one hundred and ninety-six hemiplegic patients in charge of general medicine at the Ouahigouya Regional University Hospital from November 2015 to November 2017. Results: The majority of patients had a brutal hemiplegia predominant on the right. The sample consisted mainly of male patients with a mean age of 58 years. High blood pressure was the main factor of vascular risk. The cerebrovascular accident $(58.7 \%)$ was the main pathology diagnosed. Most patients received symptomatic management. Physiotherapy was performed in $29.6 \%$ of patients. The clinical outcome at discharge was marked by the persistence of hemiplegia in more than $90.8 \%$ of patients. There was an improvement in the average MIF score at the exit. Conclusion: The lack of computed tomography and neuro-resuscitation unit were the main factors limiting the management of hemiplegia in our context.
\end{abstract}

\section{Keywords}

Hemiplegia, General Medicine, Ouahigouya

\section{Introduction}

Hemiplegia is the paralysis of a hemi-body that results in an attack of the major cortico-spinal motor pathway, either the brain or both partners. Because of the crossing of the pyramidal tract at the level of the brainstem, paralysis is found on the side opposite the brain injury. A motor aphasia is observed in case of attack of the dominant cerebral hemisphere. Hemiplegia is defined as the "more or less 
complete loss of voluntary motor function in one half of the body" according to the literature. The spasmodic or spastic hemiplegia that makes the paralyzed limbs raid and the flaccid hemiplegia that makes the paralyzed limbs softened or sluggish are translated by the occurrence at the beginning, constituting the main types. It may interest either the upper limb or the lower limb or the face or the different floors at a time. Hemiplegia can be total or partial, proportional or not related to the muscular strength of the different stages, pure (pure motor) or not (associated sensory sign). It is common and affects patients of all ages. Hemiplegia is most often seen in a stroke, which is the leading cause of acquired disability in adults and the third leading cause of death in France. Other causes are associated with it. His diagnosis is clinical. A detailed neurological clinical examination and brain imaging are essential for a diagnostic orientation and its efficient management. In the literature, the most common causes of hemiplegia are cerebrovascular accidents and head trauma. Adequate management followed by early and regular physiotherapy improves the prognosis of patients. The aim of our study was to describe the clinical and etiological characteristics of hemiplegia treated in a regional hospital in Burkina Faso.

\section{Methodology}

\subsection{Study Design}

This study took place in the general medicine department of the Ouahigouya regional university teaching hospital in the northern region of Burkina Faso. Burkina Faso is a French speaking country in West Africa. It covers $274,000 \mathrm{~km}^{2}$ with a population estimated at $16,248,558$ inhabitants, and the northern region covers $16,207 \mathrm{~km}^{2}$ with $1,185,795$ inhabitants according to 2006 Census. The overall mortality rate is $14.0 \%$ and the live expectancy at birth is 54.1 years in the northern region about Ministry of Health of Burkina Faso (2011) statistical yearbook.

\subsection{Study Population}

The study was transversal with a descriptive and analytical purpose. The study included all hemiplegic patients with muscle strength less than 5 at the onset of motor impairment of the hemi-body according to the British Medical Research Council's Muscle Score Scale, managed in the general medicine department and or seen out-of-town at the Ouahigouya Regional University Hospital Center during the period November 2015 to November 2018. All patients were examined by a neurologist from the region, the history of hemiplegia, the patients' history, the mode Installation and evolutionary hemiplegia, muscle strength, were collected. Patients who expressed a notion of partial or total motor deficit spontaneously and totally regressed and not observed were excluded from the study. Patients with incomplete clinical records were not included.

\subsection{Data Analysis}

Patient consent was collected. The data was collected on an individual informa- 
tion collection card. The data analysis was done on the software Stata 14.

\section{Results}

During the study period, 9960 patients were treated in the general medical service, all conditions combined. Our study population was studied in 196 hemiplegic patients (1.97\%). The study population consisted of 128 men (65.3\%) and 68 women (34.7\%). The average age of the patients was 58.66 years and a standard deviation of 13.41 with a minimum of 5 years and a maximum of 82 years (Figure 1). One hundred and eighty-eight (188) patients (95.9\%) had a right side and 8 patients $(4.1 \%)$ left-side.

The motor deficit occurred on exercise in 112 patients (57.1\%) and unknown in $84(42.9 \%)$ patients. It was abrupt in 121 patients $(61.7 \%)$ and progressive in 75 patients $(38.3 \%)$. The admission time to the hospital was 24 hours in 10 patients $(5.1 \%), 24$ to 72 hours in 25 patients $(12.8 \%)$ and more than 72 hours in 161 patients $(82.1 \%)$. The main vascular risk factors were arterial hypertension present in 140 patients (71.4\%), tobacco consumption in 101 patients (51.5\%), diabetes, and human immunodeficiency virus type 1 infection. and/or type 2 respectively in 65 patients (33.2\%). Hypertension was complicated by cardiac disease in 86 patients (43.9\%). The hemiplegia was of right localization in 108 patients (55.1\%), left in 72 patients (36.7\%) and bilateral in 16 patients $(8.2 \%)$.

The neurological examination at admission revealed vigilance disorders (GCS score between 12 and 8 ) in 78 patients (39.8\%), deglutition disorders in 124 patients (63.3\%), cognitive impairment in 111 patients (56.6\%) and hypoesthesia in 94 patients. Table 1 represents the socio-demographic and clinical characteristics of patients.

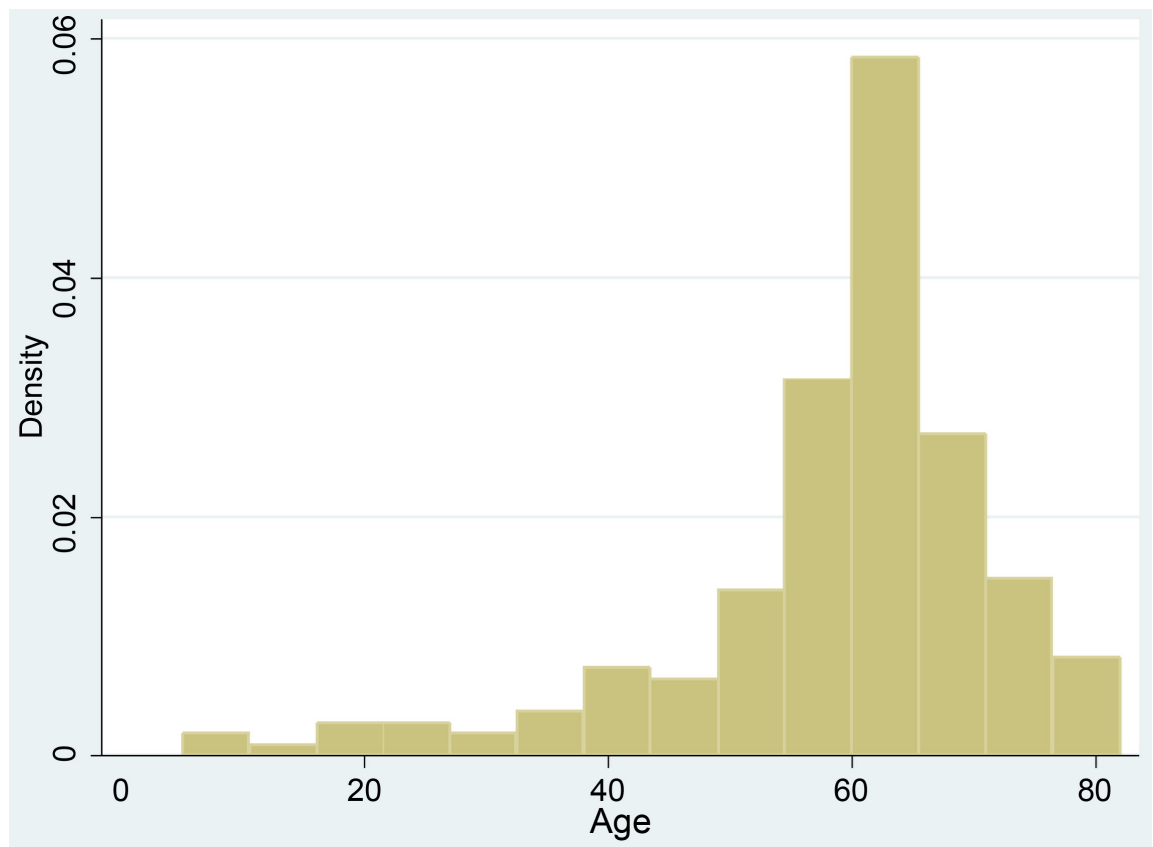

Figure 1. Age distribution of patients. Age in years; Density in percentage. 
Table 1. Socio-demographic and clinical characteristics of patients.

\begin{tabular}{|c|c|}
\hline Sociodemographic and clinical characteristics & Population study $(\mathrm{N}=196)$ \\
\hline \multicolumn{2}{|l|}{ Age group (year) } \\
\hline$<10$ & $5(2.6 \%)$ \\
\hline $11-20$ & $3(1.5 \%)$ \\
\hline $21-30$ & $11(5.6 \%)$ \\
\hline $31-40$ & $14(7.1 \%)$ \\
\hline $41-50$ & $22(11.2 \%)$ \\
\hline $51-60$ & $32(16.3 \%)$ \\
\hline $61-70$ & $56(28.6 \%)$ \\
\hline $71-80$ & $43(22 \%)$ \\
\hline$>80$ & $10(5.1 \%)$ \\
\hline Male & $128(65.3 \%)$ \\
\hline Married & $102(52 \%)$ \\
\hline Educated & $79(40.3 \%)$ \\
\hline Unschooled & $117(60.7)$ \\
\hline Laterality right & $186(95.9 \%)$ \\
\hline Left laterality & $8(4.1 \%)$ \\
\hline \multicolumn{2}{|l|}{ Risk factors } \\
\hline Hypertension & $140(71.4 \%)$ \\
\hline Diabetes mellitus & $65(36.7 \%)$ \\
\hline Obesity & $3(1.5 \%)$ \\
\hline Cigarette smoking & $101(51.5 \%)$ \\
\hline Chronic alcohol consumption & $65(33.2 \%)$ \\
\hline Sickle cell disease & $10(5.1 \%)$ \\
\hline Human Immunodeficiency Virus $1 / 2$ & $65(36.7)$ \\
\hline Hypertensive heart disease & $86(43.9 \%)$ \\
\hline Brutal hemiplegia & $121(61.7 \%)$ \\
\hline Progressive hemiplegia & $75(38.3 \%)$ \\
\hline Hemiplegia right & $108(55.1 \%)$ \\
\hline Hemiplegia left & $72(36.7 \%)$ \\
\hline Bilateral hemiplegia & $16(8.2 \%)$ \\
\hline Deglutition disorder & $124(63.3 \%)$ \\
\hline Cognitive disorder & $111(56.6 \%)$ \\
\hline
\end{tabular}

The brain scanner was performed in 46 patients $(23.5 \%)$ in the city of Ouagadougou located $180 \mathrm{~km}$ from the hospital site. The stroke was diagnosed in 27 patients $(58.7 \%)$ including 17 cases of ischemia (37\%); 10 cases of haemorrhage (22\%) and 3 cases of cerebral venous thrombosis (6.5\%). Table 2 represents the etiologies involved.

The clinical course was marked by death in 18 patients (9.2\%). Hemiplegia persisted at discharge in 178 patients (90.8\%). One hundred and three patients (52.6\%) were lost to follow-up.

Functional rehabilitation was performed in 58 patients (29.6\%). According to the MIF scale used in the functional independence measure, the mean MIF score was improved at the exit from 69.5 at admission to 89.8 at the exit.

\section{Discussion}

From this study, it appears that the hemiplegia constitutes $1.97 \%$ of all the complaints of the patients treated in the department of general medicine at the regional university hospital Ouahigouya. Hemiplegia is of more and more interest 
Table 2. Distribution of patients who performed the CT scan by etiology of hemiplegia and sex.

\begin{tabular}{cccc}
\hline & $\mathrm{N}(\%)$ & Male & Female \\
\hline ICVA & $17(37$ & $10(4127)$ & $7(318)$ \\
CVAH & $10(22)$ & $6(25)$ & $4(18.2)$ \\
CVT & $3(65)$ & $1(4.2)$ & $2(9.1)$ \\
Cerebral toxoplasmosis & $7(15)$ & $2(8.3)$ & $5(22.7)$ \\
Brain Tuberculosis & $3(6.5)$ & $1(4.2)$ & $2(9.1)$ \\
Intracranial tumor process & $6(13)$ & $4(16.6)$ & $2(9.1)$ \\
Total & $\mathrm{N}=46$ & 24 & 22
\end{tabular}

ICVA: Ischemic Cerebral Vascular Accident; CVAH: Cerebral Vascular Accident Hemorrhagic; CVT: Cerebral Venous Thrombosis.

to young people, as our series shows. Male predominance $(65.3 \%)$ is found in several series [1]-[10]. The majority of the patients had the right laterality that would be related to the severity of hemiplegia according to the literature. Indeed, this is explained by the involvement of the left major hemisphere in these patients, which includes the motor area of language. This results in language disorders with a need for speech therapy $39.8 \%$ of patients were in a coma by diffuse cerebral involvement of ascending reticular formations. The effort was the most recovered context during the installation of $51.1 \%$ hemiplegia which led to a hemorrhagic stroke. Right hemiplegia was predominant with $55.1 \%$ of patients associated with different language disorders. Arterial hypertension with 71.4 cases and smoking with $51.5 \%$ of cases were the most represented risk factors also found in the literature [4]-[11]. Patients (33.2\%) were HIV-1 and/or 2 in the northern region with a seroprevalence of $1.2 \%$. The brutal mode of occurrence was predominant in $61.7 \%$ of cases, which was the discriminating character of vascular waiting for other types of non-vascular involvement. If $5.1 \%$ of patients were seen before the first 24 hours, the majority of patients were seen beyond 72 hours or $82.1 \%$. This delay is due to the problems of transportation of patients to hospitals, which strike the short-term prognosis of patients. The most associated disorders were swallowing disorders, which also signify the severity of hemiplegia in $63.3 \%$ of cases. The difficulties encountered during the study are the lack of tomodensitometry at the regional university hospital center as well as the high cost when it is possible to evacuate the patient more than $180 \mathrm{~km}$ from the University hospital of Ouahigouya, $23.5 \%$ of patients were able to perform the CT scan as well as the absence of therapy complementary to the rehabilitation and the insufficiency of the functional evaluation [4] [6] [8] [12] [13] [14]. The hemiplegia has various causes with cerebrovascular accidents with $57.8 \%$ ischemic mechanism with $37 \%$ prevailed with a bleeding mechanism with $22 \%$ of cases. These results corroborate with those of the literature [14] [15] [16]. The infectious processes were seen in $21.5 \%$ of cases in a febrile context with a body temperature taken in the armpit greater than $38^{\circ}$ Celsius and an alteration of the 
general condition. Ninety percent $(90 \%)$ of patients still had hemiplegia at discharge. Improvement of the motor deficit is obtained at the cost of several intensive functional rehabilitation sessions [3] [5] [7] [8] [10] [13] [15] [16] [17] [18].

\section{Limitations}

Our study has limitations because of the unavailability of certain actors in the hemiplegia and CT scan in health facilities in the northern region. All the patients included in the study could not benefit from the CT scan. Also, not all our patients have benefited from an exhaustive assessment of etiological research of hemiplegia. The records of some patients were poorly maintained and incomplete, we tried to reduce this bias by taking only well-kept and complete records.

\section{Conclusion}

Hemiplegia is a more or less total loss of half-body motricity. It reflects an impairment of the central nervous system. Ischemic or hemorrhagic stroke is the main etiology of sudden hemiplegia and the leading cause of disability. It requires multidisciplinary care, involving a neurologist, a radiologist, a resuscitator, a neurosurgeon, a physiotherapist, a speech therapist, an orthoptist, an occupational therapist and a psychologist.

\section{Conflicts of Interest}

The authors declare that they have no link of interest.

\section{References}

[1] Ministry of Health of Burkina Faso (2011) Statistical Yearbook.

[2] Mwanda, O.W. (2004) Aspects of Epidemiological and Clinical Features of Patients with Central Nervous System Burkitt's Lymphoma in Kenya. East African Medical Journal, 81, S97-S103. https://doi.org/10.4314/eamj.v81i8.9213

[3] Grill, M.F. (2018) Infectious Myelopathies. Continuum (Minneap Minn), 24, 441-473. https://doi.org/10.1212/CON.0000000000000597

[4] Igun, G.O. (2000) Predictive Indices in Traumatic Intracranial Haematomas. East African Medical Journal, 77, 9-12. https://doi.org/10.4314/eamj.v77i1.46363

[5] Sá-Caputo, D.C., Costa-Cavalcanti, R., Carvalho-Lima, R.P., Arnóbio, A., Bernardo, R.M., Ronikeile-Costa, P., et al. (2016) Systematic Review of Whole-Body Vibration Exercises in the Treatment of Cerebral Palsy: Brief Report. Developmental Neurorehabilitation, 19, 327-333.

[6] Manson, J.C. and Detter, H. (1986) Abrégé de neurologie. Masson, New York, 438-464.

[7] Causes générales de l'hémiplégie. https://hemiplegieenaction.wordpress.com/2014/10/14/les-causes-generales-de-lhe $\underline{\text { miplegie/ }}$

[8] Petit, H., Lucas, L., Michel, P., Wiart, L. and Joseph, P.A. (1997) Facteurs prédictifs $\mathrm{du}$ devenir Fonctionnel après hémiplégie vasculaire. Rôle de l'albuminémie. A propos d'une Série consécutive de 115 patients. Annales de Réadaptation et de Médecine Physique, 40, 57-62. https://doi.org/10.1016/S0168-6054(97)83372-7 
[9] Doin, G., et al. (1957) Precis de neurologie, RIMAUDL. 6eme edition, Collection TESTUI, 50-51, 71-79.

[10] Assi, B., Datie, A.M., Kouassi, E.B. and Manou, K.B. (2002) Problèmes liés à la prise en charge Rééducative des hémiplégies vasculaires à Abidjan.

[11] Napon, C., Tougma, L., Kaboré, R. and Kaboré, J. (2013) Prognosis for Motor Deficits after Strokes in Burkina Faso. Médecine et Santé Tropicales, 23, 320-323. https://doi.org/10.1684/mst.2013.0232

[12] Jalal, B. and Hinton, D.E. (2013) Rates and Characteristics of Sleep Paralysis in the General Population of Denmark and Egypt. Culture, Medicine, and Psychiatry, 37, 534-548. https://doi.org/10.1007/s11013-013-9327-x

[13] Roques, C.F., Le Vourc'h, P., Marque, P., et al. (1996) Pronostic Vital de patients rééduqués après hémiplégie Vasculaire. Annales de Réadaptation et de Médecine Physique, 39, 547-551. https://doi.org/10.1016/S0168-6054(97)84238-9

[14] Etude Epidémio clinique de l'hémiplégie de l'enfant au service de Pédiatrie du CHU Gabriel Touré/Sante/malimed/2008/38d.pdf.

[15] Vincent-Onabajo, G.O., Hamzat, T.K. and Owolabi, M.O. (2014) Are There Gender Differences in Longitudinal Patterns of Functioning in Nigerian Stroke Survivors during the First Year after Stroke? Neurorehabilitation, 34, 297-304. https://doi.org/10.3233/NRE-141047

[16] Assadeck, H., ToudouDaouda, M., Mamadou, Z., Moussa Konate, M., HassaneDjibo, F. and DoumaMaiga, D. (2019) Hemiconvulsion-Hemiplegia-Epilepsy Syndrome in Niger: A Retrospective Case Series. Journal of Clinical Neuroscience, 65 , 121-124. https://doi.org/10.1016/j.jocn.2019.03.008

[17] Profil épidémiologique des affections neurologiques au Gabon P Le Bigot 1993. http://books.google.com

[18] Nandjui, B.M., Datie, A.M. and Tuo, B. (1996) Profil epidemiologique des hemiplegies en Reeducation. Médecine d'Afrique Noire, 43. 